\title{
Use of benzodiazepines increased road traffic accidents whereas use of tricyclic antidepressants and SSRIs did not
}

\author{
Barbone F, McMahon AD, Davey PG, et al. Association of road-traffic accidents with benzodiazepine use. Lancet 1998 Oct \\ 24;352:1331-6.
}

\section{Question}

Is psychoactive drug use associated with an increased risk of road traffic accidents?

\section{Design}

A case crossover study.

\section{Setting}

Tayside region, UK.

\section{Participants}

1731 people $(55 \%$ men) who were $\geqslant 18$ years of age, had a first road traffic accident between 1 August, 1992 and 30 June, 1995, and had used a psychoactive drug during the study period.

\section{Assessment of risk factors}

Data on psychoactive drug use (benzodiazepines [anxiolytics and hypnotics] including zopiclone, tricyclic antidepressants [TCA], selective serotonin reuptake inhibitors [SSRI], and other psychoactive drugs) were extracted from the medicines monitoring unit's database. Participant characteristics were also collected.

\section{Main outcome measure}

A first road traffic accident (identified using Tayside police records) while using a psychoactive drug.

\section{Main results}

On the day of the first road traffic accident, 235 participants were using benzodiazepines, 189 were using TCAs, 84 were using SSRIs, and 47 were using other psychoactive drugs. The risk of a first road traffic accident was increased with benzodiazepines but not with TCAs or SSRIs drug use (table). Among users of benzodiazepines, the risk of an accident was increased for people $<44$ years of age, if the police officer judged the driver to be at fault, and if the alcohol breath test was positive. No difference was shown for men and women or people $\geqslant 45$ years of age. The risk of accident was increased with anxiolytic, short acting benzodiazepines (only zopiclone was evaluated), and long acting benzodiazepines. Hypnotics and intermediate acting benzodiazepines did not increase risk.

\section{Conclusion}

All benzodiazepines increased the risk of a first road traffic accident but tricyclic antidepressants or selective serotonin reuptake inhibitors drugs did not.

Risks of a first road traffic accident while using psychotropic drugs

\begin{tabular}{ll}
\hline Drug & Odds ratio $(95 \%$ CI $)$ \\
\hline Benzodiazepines & $1.6(1.2$ to 2.1$)$ \\
Tricyclic antidepressants & $0.9(0.7 \text { to } 1.2)^{*}$ \\
Selective serotonin reuptake inhibitors & $0.9(0.6 \text { to } 1.3)^{*}$ \\
\hline
\end{tabular}

*Not significant.

Source of funding: SmithKline Beecham.

For correspondence:Dr T M MacDonald, Medicines Monitoring Unit, Department of Clinical Pharmacology and Therapeutics, University of Dundee, Ninewells Hospital and Medical School, Dundee DD1 9SY,UK. Fax +44 (0)1382642637.

Modified abstract also published in ACP Journal Club.

\section{Commentary}

Road traffic accidents account for $>5000$ deaths annually in the UK alone, so any study investigating their causes is welcomed. In considering the role of psychotropic drugs in road traffic accidents, it has been "practically impossible to know whether [drugs] are the cause of the accidents because underlying ... pathologies can equally create problems such as lack of attention ..." In addition to underlying illness, there are many other confounders, including chronobiological variables (performance related to time of day or night), personality, and environmental factors. It is therefore extremely difficult to quantify precisely the contribution of psychoactive drugs to road traffic accidents by using conventional case control methods, which has been the Achilles' heel of previous studies.

In contrast with earlier studies, the strength of this study by Barbone et al lies in its robust design; participants were used as their own controls, such that for each driver, the risks of a road traffic accident when exposed and not exposed to medication are compared. Interestingly, this reflects a growing trend in other areas of research (eg, repeat measures designs in the neuroimaging of changing clinical states), as this significantly increases statistical power. These results may therefore be considered meaningful. The main drawbacks relate to lack of information about secondary non-compliance, time interval between last dose and the road traffic accident, and underlying illness and personality. Given the large numbers of subjects $(n=1731)$ and the case crossover design, however, such variables are unlikely to have substantially affected the results.

GABA-ergic sedatives are clearly shown to be associated with an increased risk of road traffic accidents, whereas SSRIs are not (and interestingly, nor are tricyclics, which runs contrary to previously held notions ${ }^{2}$ ). In terms of clinical practice, perhaps we need not be so worried about patients driving while taking tricyclics, but the evidence about benzodiazepines and zopiclone is clear: patients prescribed these drugs should routinely be advised of the risks of driving, in line with current recommendations. ${ }^{3}$

Bruce Moore, MB, ChB, MRCPsych Royal Liverpool University Hospital Liverpool, UK

1 Lemoine P, Ohayon M. Abuse of psychotropic drugs while driving. Encephale 1996;22:1-6.

2 Hale AS. The importance of accidents in Hale AS. The importance of accidents in
evaluating the costs of SSRIs: a review. Int J evaluating the costs of SSRIs: a revie
Clin Psychopharmacol 1994;9:195-201.

3 Taylor JF. Medical aspects of fitness to drive. 5th edition. London: Medical Commission on Accident Prevention, 1995. 